(3)

Volume 12, 2017

\title{
ENTERPRISE ONTOLOGY MODEL FOR TACIT KNOWLEDGE EXTERNALIZATION IN SOCIO-TECHNICAL ENTERPRISES
}

\begin{tabular}{lll}
\hline Shreyas Suresh Rao* & $\begin{array}{l}\text { Manipal Institute of Technology, } \\
\text { Manipal University, Manipal, India }\end{array}$ & shreyassureshrao@gmail.com \\
Ashalatha Nayak & $\begin{array}{l}\text { Manipal Institute of Technology, } \\
\text { Manipal University, Manipal, India }\end{array}$ & asha.nayak@manipal.edu \\
* Corresponding author & &
\end{tabular}

\section{ABSTRACT}

Aim/Purpose

A vital business activity within socio-technical enterprises is tacit knowledge externalization, which elicits and explicates tacit knowledge of enterprise employees as external knowledge. The aim of this paper is to integrate diverse aspects of externalization through the Enterprise Ontology model.

Background

Across two decades, researchers have explored various aspects of tacit knowledge externalization. However, from the existing works, it is revealed that there is no uniform representation of the externalization process, which has resulted in divergent and contradictory interpretations across the literature.

Methodology The Enterprise Ontology model is constructed step-wise through the conceptual and measurement views. While the conceptual view encompasses three patterns that model the externalization process, the measurement view employs certainty-factor model to empirically measure the outcome of the externalization process.

Contribution The paper contributes towards knowledge management literature in two ways. The first contribution is the Enterprise Ontology model that integrates diverse aspects of externalization. The second contribution is a Web application that validates the model through a case study in banking.

Findings The findings show that the Enterprise Ontology model and the patterns are pragmatic in externalizing the tacit knowledge of experts in a problem-solving scenario within a banking enterprise.

Recommendations Consider the diverse aspects (what, where, when, why, and how) during the tacit for Practitioners knowledge externalization process.

Accepting Editor: Salah Kabanda | Received: November 1, 2016 | Revised: January 12, February 7, March 1, 2017 | Accepted: March 2, 2017.

Cite as: Rao, S. S.; \& Nayak, A.. (2017). Enterprise ontology model for tacit knowledge externalization in sociotechnical enterprises. Interdisciplinary Journal of Information, Knowledge, and Management, 12, 99-124. Retrieved from http://www.informingscience.org/Publications/3680

(CC BY-NC 4.0) This article is licensed it to you under a Creative Commons Attribution-NonCommercial 4.0 International License. When you copy and redistribute this paper in full or in part, you need to provide proper attribution to it to ensure that others can later locate this work (and to ensure that others do not accuse you of plagiarism). You may (and we encourage you to) adapt, remix, transform, and build upon the material for any non-commercial purposes. This license does not permit you to use this material for commercial purposes. 
Future Research To extend the Enterprise Ontology model to include externalization from partially automated enterprise systems.

Keywords tacit knowledge, enterprise ontology, socio-technical enterprise, externalization, certainty-factor

\section{INTRODUCTION}

Socio-technical enterprises are business organizations which regard buman knowledge as the key asset in the functioning of an enterprise. Some examples are banking, education, and healthcare enterprises which are predominantly human-intensive (Booch, 2010) and use human knowledge in decision making, business innovation, and problem solving activities ( $\mathrm{Li} \& \mathrm{Lu}, 2007$ ). Since the growth of these enterprises is often marred by uncontrollable factors such as uncertain economic conditions, attrition, or retirement of highly-valued employees (Chandra, Iyer, \& Raman, 2015; Whyte \& Classen, 2012), knowledge creation is recognized as a vital business activity that counters these factors (Aming'a, 2015; Richards \& Busch, 2003).

Typically, knowledge within socio-technical enterprises is expressed using an iceberg metaphor (Serrat, 2008). As per the metaphor, enterprise knowledge is viewed as a dichotomous split between tacit and explicit, with tacit occupying $80 \%$ of the area submerged under the water and explicit as $20 \%$ visible outside the surface of the water. In retrospect, the metaphor implies that $80 \%$ of an enterprise's knowledge is contained within the minds of its employees as tacit knowledge. Hence, tacit knowledge represents the unarticulated know-how developed over time by employees through experiences derived from everyday work, dealing with clients, following company procedures (Friedrich \& van der Poll, 2007), etc. Only 20\% of the enterprise's knowledge is expressed externally through documents and storage repositories as explicit knowledge.

As enterprise knowledge is largely tacit and perhaps underutilized, it is vital to convert this knowledge into an explicit format to facilitate knowledge utilization. The process of tacit knowledge elicitation from employees' minds and subsequent explication into explicit format is referred to as Tacit Knowledge Externalization (TKE) (Nonaka \& Takeuchi, 1995). Almost always, the process of externalization is initiated by a knowledge seeker in the enterprise with the intention of utilizing the expert's tacit knowledge to solve enterprise challenges (Khan \& Khader, 2014). Accordingly, the seeker engages the knowledge expert in a constructivist interaction, resulting in knowledge explication.

Since the time Nonaka \& Takeuchi (1995) first coined the term "externalization", researchers have explored various aspects of externalization, namely, (a) lifecycle (Dalkir, 2005; Whyte \& Classen, 2012), (b) elicitation methods (Acosta et al., 2004; Al-Qdah \& Salim, 2013), (c) inter-actor collaboration (Chandra et al., 2015; Khan \& Khader, 2014), and (d) externalization scenarios (Leonard \& Insch, 2005; Sigala \& Chalkiti, 2007). Although researchers have explored diverse aspects of externalization individually, there have been no attempts for its comprehensive integration (Echajari \& Thomas, 2015). This lacuna has resulted in a divergent and contradictory representation of the externalization process (Munoz, Mosey, \& Binks, 2015; Venkitachalam \& Busch, 2012).

The paper proposes an Enterprise Ontology (EO) model for integrating diverse aspects of externalization. The EO model is based on the theory of Enterprise Ontology (Dietz, 2006), which provides formal models and patterns for representing any business operation within an enterprise. Since externalization is also perceived as a vital business operation within the enterprise (Sigala \& Chalkiti, 2007), the proposed model is relevant in solving the externalization lacuna.

Okafor and Osuagwu (2006) identified two types of knowledge externalization, namely, manual and automated (or machine learning). The scope of this research is of the first kind, wherein the experts' knowledge is manually elicited.

The paper contributes towards existing literature by systematically investigating diverse aspects of externalization using Kipling's 5W+1H (What, Where, When, Why, Who, and How) approach (Jia, 
Cai, Yu, \& Tse, 2016). The second contribution of the research is the Enterprise Ontology model that comprehensively integrates diverse aspects of externalization through three patterns, namely, transaction pattern, extended transaction pattern, and interaction pattern. The model also includes a certaintyfactor based empirical measurement for the TKE outcome, which substantiates the quality of the externalized tacit knowledge. The third contribution is the Web application titled ExtApp that validates the EO model for a problem solving scenario in a banking case study. Lastly, the EO model is applied in various externalization scenarios, such as capture-while-doing, open innovation, and processbased scenarios, which demonstrates the extensibility of the research work.

\section{LITERATURE REVIEW}

Polanyi (1966) described tacit knowledge (TK) with the postulate "we can know more than we can tell", which implies that TK is contained in the minds of people as cognitive skills and technical know-how that is difficult to articulate. Furthermore, he classified human knowledge into three categories of (a) non-specifiable tacit knowledge, (b) non-specified tacit knowledge, and (c) explicit knowledge. While category (a) represents personalized TK that cannot be articulated, category (b) represents TK that has the potential for articulation as explicit knowledge and is the scope of this research. Nonaka \& Takeuchi (1995) proposed the SECI (Socialization, Externalization, Combination, Internalization) model wherein the socialization process helps in transferring TK between employees of an enterprise, through activities such as observation, mentoring, analogies, metaphors (AlQdah \& Salim, 2013; Nonaka \& Takeuchi, 1995), etc. These activities facilitate TK conversion within category (b). Although the socialization process helps one to acquire knowledge, the knowledge persists in inarticulable format and does not benefit the entire enterprise.

The limitation of inarticulable knowledge representation is overcome through the externalization process wherein employees' or experts' tacit knowledge and experiences are elicited through interaction and converted to articulable format, which can be shared within the enterprise. Thus, externalization achieves knowledge conversion from category (b) to (c). Elaborating further, the elicited tacit knowledge during externalization process can be work-related, self-related, or social in nature (Haron, Noordin, \& Alias, 2010), and the quality of elicited knowledge depends on the cognitive skills, self-knowledge, emotional resilience, and personal drive of the employee bearing the tacit knowledge (Choudrie \& Selamat, 2006).

We have adopted Kipling's 5W+1H approach (Jia et al., 2016) to systematically identify various aspects of externalization. Since the socio-technical enterprise represents the Where aspect of externalization, the surveyed literature attempts to answer other Kipling's questions of Why, When, What, Who, and How, as described in the following.

\section{MOTIVATIONAL FACTORS (WHY) AND SCENARIOS (WHEN) FOR EXTERNALIZATION}

There are many factors which motivate the externalization process in socio-technical enterprises (Chandra et al., 2015; Jackson, 2010; Sigala \& Chalkiti, 2007). The anticipated retirement of a large faction of "baby boomer" generation experts (born post 1939-1945 World War) across the world in the next ten years, presents a knowledge crisis within enterprises (Jackson, 2010). The experts' scarce and valuable tacit knowledge, amounting to nearly 30-40 years, needs conservation. Since the experts' tacit knowledge includes social, cognitive, and technical dimensions that comprise approximately $80 \%$ of the enterprise's knowledge (Serrat, 2008), it is important to externalize the tacit knowledge from the baby boomer generation. Another significant factor is the attrition of highly-valued employees from the enterprise, whose tacit insights and experiences are vital to manage uncertain economic conditions (Chandra et al., 2015). In banking and insurance sectors, employees with rich tacit experience often negotiate better job positions and/or higher salaries (Sigala \& Chalkiti, 2007). Hence from an economic perspective, it is imperative for enterprises to externalize and thereby retain employees' tacit knowledge. 
Socio-technical enterprises employ externalization process in strategic decision making, problem solving, experience sharing, business innovation, and business performance enhancement scenarios (Leonard \& Insch, 2005; Li \& Lu, 2007). The Deloitte Millennial survey (Deloitte, 2015) augments the fact that global leaders have selected strategic thinking (39\%), problem solving (39\%), and decisiveness $(30 \%)$ as important drivers in leading an enterprise. The survey further acknowledges the role of externalization as an effective mechanism for tacit knowledge capture in these scenarios.

Experience sharing is the most common scenario for externalization, which involves sharing experiences in the form of best practices (Friedrich \& van der Poll, 2007), stories (Acosta et al., 2004), and project knowledge (Chandra et al., 2015). It is observed that certain scenarios, such as strategic thinking and problem solving, mandate the participation from multiple experts, whereas other scenarios, such as decisiveness and enterprise blogging, need only a single expert for the externalization process.

\section{LIFECYCLE OF EXTERNALIZATION PROCESS (WHAT)}

Researchers have proposed process-based lifecycles (Dalkir, 2005; Whyte \& Classen, 2012) and problem-based lifecycles (Andreasik, 2007; Martinho \& Silva, 2012; Ocegueda-Miramontes \& JuarezRamirez, 2013) for externalization.

Whyte \& Classen (2012) proposed a process-based lifecycle which involves six phases: selection of a complex research question, interviewing relevant subject matter experts and eliciting their story, coding the stories into external knowledge, analysis of the stories, validation using Delphi techniques, and, finally, categorization of the explicit knowledge under predefined knowledge clusters. Dalkir (2005) proposed a process-based lifecycle for knowledge externalization comprising of four phases: identifying the critical knowledge to explicate, acquiring the tacit knowledge through elicitation method, refining the acquired knowledge, and, lastly, storing the knowledge in a knowledge base.

Ocegueda-Miramontes \& Juarez-Ramirez (2013) proposed a problem-based lifecycle for externalization wherein first, an enterprise problem is identified. Second, possible answers to the problem are elicited from the tacit knowledge of enterprise experts, and third, a certainty-factor based reasoning approach is applied to analyze and choose the best answers. Andreasik (2007) discusses a problembased lifecycle called Case-based Reasoning (CBR) to solve new cases (problems) based on the solutions of similar past cases. A typical CBR lifecycle comprises five stages of retrieve, reuse, revise, review, and retain. First, a target problem is identified to be solved. Second, similar cases are retrieved from knowledge store, mapped to the target problem, and a revised solution is construed, if necessary. Next, the revised solution is reviewed and retained (stored) in the knowledge repository as new knowledge to solve the targeted case.

Martinho \& Silva (2012) proposed a non-intrusive approach for tacit knowledge externalization known as capture-while-doing. In their approach, first, an end-user identifies an enterprise goal which requires externalization from other end-users for fulfilment. Subsequently, the end-user adopts an ad hoc request-response collaboration with other end-users, capturing and aggregating their tacit knowledge in the process, until the enterprise problem is completely solved. While the CBR and certainty factor approaches discussed previously represent systematic lifecycles for problem-based externalization, the capture-while-doing approach uses an ad hoc and people-driven methodology.

While problem-based lifecycles typically solve an enterprise problem employing externalization process, process-based lifecycles are more generic and used in scenarios such as decision making and experience sharing.

\section{METHODS OF EXTERNALIZATION (HOW)}

Some popular methods of externalization include (a) interviewing experts regarding an issue/problem and documenting their opinions; (b) joint application design wherein the expert and the novice seeking knowledge, jointly engineer a product/application; (c) conducting brainstorming sessions in an enterprise and documenting the responses; (d) documenting best practices followed in project execution; and (e) 
narrative technique, where an expert is asked to narrate his/her experiences on an event (Dzekashu, 2015; Friedrich \& van der Poll, 2007).

Concept maps (Acosta et al., 2004) are used to capture tacit knowledge in the form of group storytelling activity, wherein subject matter experts (SMEs) share their experiences via storytelling to create a concept map that provides a semantic and visual representation of the whole story. Sigala and Chalkiti (2007) used questionnaires and telephonic interviews as methods to elicit tacit knowledge from hotel staff in order to improve the business processes in the hotel industry. Whyte and Classen (2012) proposed a storytelling approach for externalization from subject matter experts. In their approach, the SMEs could choose a story type that could be anecdotal, chronicle, or project related and describe their experiences in semi-structured interviews. Their interviews were coded, analyzed, and allotted to predefined knowledge management (KM) clusters based on Delphi techniques.

More recently, with the advent of Web 2.0 technologies, the process of externalization is turning net centric (Pham \& Hara, 2009) and employs technologies such as enterprise blogs, wikis, and social media tagging for the elicitation of expert tacit knowledge (Chatti, Klamma, Jarke, \& Naeve, 2007). The Web 2.0 medium facilitates immediate exchange of inherently tacit ideas and opinions which are reflected in e-learning systems that employ instant messaging, emails, and discussion forums to explicate expert knowledge (Khan \& Khader, 2014). Li and Lu (2007) proposed a combination of three Web 2.0 technologies, namely, Blog, RSS (Really Simple Syndication), and Wikipedia, for externalization. Enterprise bloggers can share their tacit knowledge on any topic via a blog-based micro content platform. RSS aggregator component is used to syndicate multiple blog data automatically and allows end-users to view the data via RSS reader. Lastly, the blog data is stored in local Wiki which acts as a knowledge repository.

\section{ACTOR INVOLVEMENT IN THE EXTERNALIZATION PROCESS (WHO)}

Tacit knowledge externalization is essentially an interaction between two kinds of actors, namely, knowledge seekers and knowledge providers (Khan \& Khader, 2014). The knowledge providers can represent individual experts, group of experts, or communities of practice within an enterprise (Ye \& Zhi-ping, 2006). Furthermore, the tacit knowledge elicited from communities of practice and groups within an enterprise can be termed as group tacit knowledge (Erden, von Krogh, \& Nonaka, 2008).

A summary of this section is presented in Table 1, which categorizes various aspects of tacit knowledge externalization under process-based and problem-based life cycle categories.

Existing literature covers diverse aspects of externalization. However, there have been no attempts for the uniform representation of the externalization process (Echajari \& Thomas, 2015) by integrating the diverse aspects. This has resulted in divergent and contradictory representation of externalization in the literature (Munoz et al., 2015; Venkitachalam \& Busch, 2012). Hence the goal of this research is to generalize the process of externalization by integrating its diverse aspects, which is demonstrated through the EO model in the next section.

\section{EO MODEL FOR EXTERNALIZATION}

The EO model is constructed stepwise in the form of views, where a view is defined as a simplified model of a system that addresses a specific concern regarding the system (Kruchten, 1995). The two important concerns of this research are to integrate diverse aspects of externalization and, as a consequence, to measure empirically the outcome of the externalized knowledge. Accordingly, the EO model comprises conceptual and measurement views, wherein the former generalizes the process of externalization and the latter empirically measures the outcome of the process, as shown in Figure 1. 
Table 1. Summary of Tacit Knowledge Externalization literature

\begin{tabular}{|c|c|c|}
\hline ASPECT & PROCESS-BASED LIFE CYCLE & PROBLEM-BASED LIFE CYCLE \\
\hline Phases & $\begin{array}{l}\text { - } \\
\text { - Interview relevant subject matter ex- } \\
\text { perts and elicit their stories } \\
\text { - } \quad \text { Code the stories into external } \\
\text { knowledge } \\
\text { - Analyze the stories } \\
\text { - Validate using techniques such as } \\
\text { Delphi } \\
\text { - Categorize the explicit knowledge } \\
\text { under predefined knowledge clusters }\end{array}$ & $\begin{array}{l}\text { - Identify an enterprise problem } \\
\text { Elicit possible answers to the } \\
\text { problem from the tacit } \\
\text { knowledge of enterprise } \\
\text { experts or from past cases } \\
\text { - Apply any reasoning approach } \\
\text { such as certainty-factor model } \\
\text { to rate and choose the best, } \\
\text { average, and worst answers } \\
\text { - Categorize the answers under } \\
\text { predefined knowledge clusters. }\end{array}$ \\
\hline $\begin{array}{l}\text { Methods } \\
\text { employed }\end{array}$ & $\begin{array}{l}\text { - } \text { Questionnaires and Interviewing } \\
\text { - } \quad \text { Ctorytelling } \\
\text { - Wikis and Social media }\end{array}$ & $\begin{array}{ll}\text { - } & \text { Interviewing } \\
\text { - } & \text { Joint application design } \\
\text { - } & \text { Enterprise blogs }\end{array}$ \\
\hline Scenarios & $\begin{array}{ll}\text { - } & \text { Decision making } \\
\text { - } & \text { Experience sharing }\end{array}$ & $\begin{array}{l}\text { - Problem solving } \\
\text { - Business innovation }\end{array}$ \\
\hline $\begin{array}{l}\text { Typical } \\
\text { Actors }\end{array}$ & $\begin{array}{l}\text { - } \text { Individual expert } \\
\text { - Group of experts } \\
\text { - } \quad \text { Communities of practice }\end{array}$ & $\begin{array}{l}\text { - Individual expert } \\
\text { - Group of experts }\end{array}$ \\
\hline
\end{tabular}

\begin{tabular}{|c|c|c|c|c|c|}
\hline Measurement View & \multicolumn{5}{|c|}{ Certainty-Factor Model } \\
\hline Conceptual View & $\begin{array}{l}\text { Tran } \\
\text { Patte }\end{array}$ & $\begin{array}{l}\text { action } \\
\text { n }\end{array}$ & $\begin{array}{l}\text { Extende } \\
\text { Transact } \\
\text { Pattern }\end{array}$ & & $\begin{array}{l}\text { Interaction } \\
\text { Pattern }\end{array}$ \\
\hline Externalization Aspects & Domain & Scenarios & Lifecycle & $\begin{array}{l}\text { Elicitation } \\
\text { Methods }\end{array}$ & $\begin{array}{l}\text { Actor } \\
\text { Involvement }\end{array}$ \\
\hline Externalization Process & \multicolumn{2}{|c|}{ Tacit Knowledge } & Conversion & \multicolumn{2}{|c|}{ Explicit Knowledge } \\
\hline
\end{tabular}

Figure 1. Enterprise Ontology Model

Figure 1 depicts four layers, with the lowest layer showing the basic externalization process of tacit to explicit knowledge conversion. The second layer depicts different aspects of the externalization process, namely, lifecycle (what), scenarios (when), elicitation methods (how), actor involvement (who), and domain (where). 
The third layer depicts the conceptual view, which adopts the theory of Enterprise Ontology (Dietz, 2006) to generalize the externalization process. Externalization can be viewed as a vital operation in socio-technical enterprises comprising two important actions. One is the interactions between the knowledge seekers and experts during the externalization process. Second is the production of explicit knowledge as an outcome of the externalization process.

The theory of Enterprise Ontology defines formal models and patterns for representing interactions and outcomes of any operation within an enterprise (Dietz, 2006). The models and patterns depict human-human, human-system interactions via coordination acts, and the outcome of operations via production acts. Hence, we have adopted the Enterprise Ontology models and patterns to generalize the externalization process.

The outcome of the externalization process is subjective in nature, as it depends on the expert's tacit experiences and skills, which are personalized. Hence, there exists an element of uncertainty in the outcome, since the beliefs and disbeliefs of the experts influence the outcome of the externalization process. The fourth layer, the measurement view, employs certainty-factor model to measure the uncertain outcome of the externalization process.

\section{CONCEPTUAL VIEW}

The conceptual view comprises three patterns. The transaction pattern outlines the generic externalization scenario in any socio-technical enterprise. The second pattern, the extended transaction pattern, describes the lifecycle of a typical externalization process by extending the transaction pattern. Lastly, the interaction pattern depicts various actors involved in the externalization process, along with their interactions. Collectively, the three patterns integrate the when, what, how, and who aspects of externalization as described in detail in the following.

\section{Transaction pattern (When aspect)}

The transaction pattern describes the generic externalization scenario occurring in any sociotechnical enterprise. According to the pattern, we refer to the knowledge seeker as the Initiator / Requestor role and the knowledge provider as the Executor / Solver role, as depicted in Figure 2. The interactions between the Requestor and the Solver are referred as coordination acts, and the production of explicit knowledge is referred as a production act. The focus of this pattern is to describe when the coordination acts and production acts occur during a typical externalization scenario.

The process of externalization can be represented as a transaction (T01) between the Requestor and the Solver, across three phases of Order, Execute, and Result. While Order and Result are primarily coordination phases between the Requestor and the Solver, the Execute phase results in the actual externalization of the tacit knowledge of the Solver.

In a happy scenario, the transaction T01 starts with the Requestor's coordination act $(<\mathrm{rq}\rangle)$ where he/she requests the Solver for sharing his/her tacit knowledge. The Solver promises the Requestor for sharing the tacit knowledge through the act $(<\mathrm{pm}>)$. Subsequently, the Solver makes explicit his/her tacit knowledge in the form of an explicit deliverable, notified as a production act $(<\mathrm{T} 01$ is executed $>$ ) and communicates the completion of the production act to the Requestor as an act $(<$ st $>)$. Lastly, the Requestor accepts the explicit deliverable from the Solver through the act $(<\mathrm{ac}>)$. Some cancellation acts that can occur include the Solver declining $(<\mathrm{dc}>)$ to accept the initial request, which is eventually allowed $(<\mathrm{al}>)$ by the Requestor; the Solver refusing $(<\mathrm{rf}>)$ to hand-over the explicit knowledge deliverable, either because the knowledge is too personal to be shared or due to some exigent conditions; the Requestor rejecting $(<\mathrm{rj}>)$ the explicit deliverable, since it may not meet the expectations.

The Order phase comprises $<\mathrm{rq}>$ and $<\mathrm{pm}>$ acts under a happy scenario, while acts such as $<\mathrm{dc}>$ and $<$ al $>$ are used during cancellations. The Execute phase comprises a single production act $<\mathrm{T} 01$ is executed $>$. Lastly, the Result phase comprises $<$ st $>$ and $<$ ac $>$ acts in a happy scenario. The cancel- 
lation scenarios in Result phase can either be $<\mathrm{rf}>$ and $<$ al $>$ for Solver refusal or $<\mathrm{rj}>$ for Requestor rejection of the deliverable.

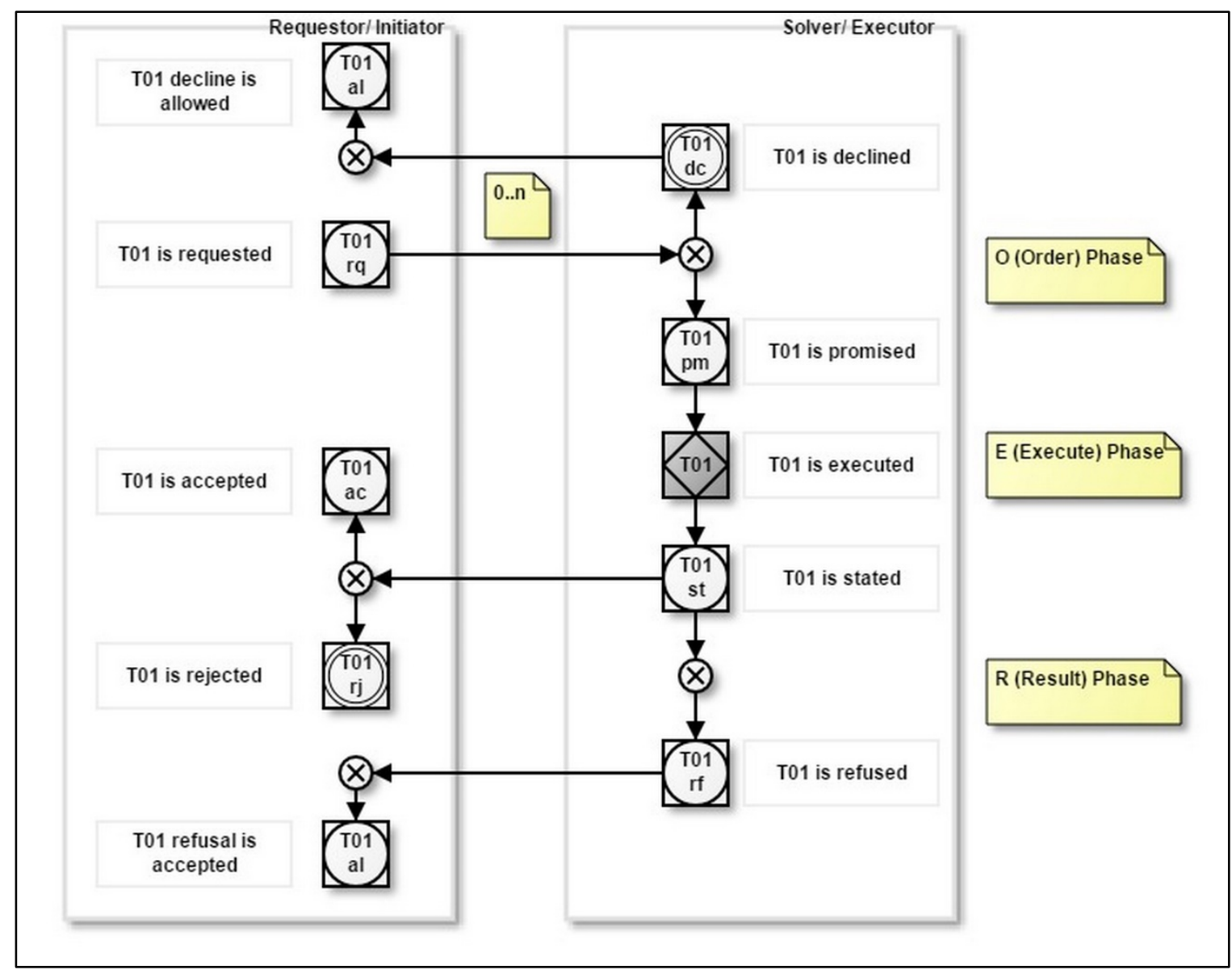

Figure 2. Transaction Pattern

It is quite common in enterprises to seek tacit knowledge externalization from multiple Solvers (experts). Accordingly, in the following, we present four variant scenarios of the transaction pattern:

- SISE (Single Initiator Single Executor) - The externalization process is initiated by a single seeker of tacit knowledge and executed by a single expert or a group within the enterprise.

- SIME (Single Initiator Multiple Executor) - The externalization process is initiated by a single seeker and executed by multiple individual experts.

- MISE (Multiple Initiator and Single Executor) - The externalization process is initiated by multiple seekers/groups and executed by a single expert.

- $\quad$ MIME (Multiple Initiator and Multiple Executor) - The scenario involves multiple seekers and multiple experts.

\section{Extended transaction pattern (What and How aspects)}

The transaction T01, described in the transaction pattern, represents a generic and aggregated transaction, which in turn can be decomposed into a set of eight transactions (T1 to T8) that form the extended transaction pattern, as shown in Table 2. All the transactions are generic and act as placeholders for different lifecycle stages discussed under literature review. Each transaction represents a unique lifecycle stage in externalization. Furthermore, all transactions are defined according to 
WOSL (World Ontology Specification Language) terminologies, since WOSL is recognized as a standard for expressing transactions in enterprise systems (Dietz, 2006).

In Table 2, we have used a general term "case" to indicate an instance of a particular situation that needs tacit knowledge elicitation from experts. In reality, the case represents an issue in a problem solving scenario, innovation challenge in a business innovation scenario, a topic in an experience sharing scenario, and alternatives in a decision making scenario.

Furthermore, in Table 2, the column "result type" depicts the outcome of the respective transaction in terms of categories and association types. According to WOSL, a category refers to a primal type which contains two types of associations, namely, stata and facta. A stata type is a constant, whose existence is timeless. For example, the tacit knowledge $\mathrm{K}$ that has been elicited in transaction T4 is of type "stata", since the knowledge can be preserved permanently. On the other hand, a "facta" type comes into existence because of an event, and its existence is volatile. For example, transaction T2 indicates that a case of category $\mathrm{C}$ has been started, and after the occurrence of transactions $\mathrm{T} 3$ to $\mathrm{T} 6$, the case ends in transaction T7.

The lifecycle of a typical externalization process starts with T1 (Case Formulation) transaction. In this transaction, the reasons for initiating the externalization process and the detailed action plan for executing the process is captured as case C. The transactions T2 (Case Start) and T7 (Case End) indicate the boundary events for case $\mathrm{C}$, within which the externalization process unfolds. In transaction T3 (Case Assign), first, subject matter expert(s) (SME) are identified, whose tacit knowledge needs to be externalized in order to solve the case C. Subsequently, the case is assigned to the expert(s). Next, the process of tacit knowledge elicitation is conducted as part of transaction T4 (TK Elicit), which results in the explicit knowledge $\mathrm{K}$.

Table 2. Extended Transaction Pattern represented in Transaction-Result Form

\begin{tabular}{|c|c|c|c|}
\hline ID\# & TRANSACTION & RESULT TYPE & $\begin{array}{l}\text { CATEGORY AND ASSOCIA- } \\
\text { TION TYPES }\end{array}$ \\
\hline T1 & Case Formulation & Case $\mathrm{C}$ has been formulated & $\begin{array}{l}\text { C is a category, association type is } \\
\text { stata }\end{array}$ \\
\hline $\mathrm{T} 2$ & Case Start & Case $\mathrm{C}$ has been sta & $\begin{array}{l}\mathrm{C} \text { is a category, association type is } \\
\text { facta }\end{array}$ \\
\hline T3 & Case Assign & $\begin{array}{l}\text { Case } \mathrm{C} \text { has been assigned to } \\
\text { Expert } \mathrm{E}\end{array}$ & $\begin{array}{l}\mathrm{C} \text { and } \mathrm{E} \text { represent categories, } \\
\text { association type is stata }\end{array}$ \\
\hline T4 & TK Elicit & $\begin{array}{l}\text { Tacit Knowledge K has been } \\
\text { elicited }\end{array}$ & $\begin{array}{l}\mathrm{K} \text { is a category, association type is } \\
\text { stata }\end{array}$ \\
\hline T5 & Knowledge Synthesis & $\begin{array}{l}\text { Knowledge K has been } \\
\text { synthesized }\end{array}$ & $\begin{array}{l}\mathrm{K} \text { is a category, association type is } \\
\text { stata }\end{array}$ \\
\hline T6 & Knowledge Evaluation & $\begin{array}{l}\text { Knowledge } \mathrm{K} \text { has been } \\
\text { evaluated }\end{array}$ & $\begin{array}{l}\mathrm{K} \text { is a category, association type is } \\
\text { stata }\end{array}$ \\
\hline $\mathrm{T} 7$ & Case End & Case $\mathrm{C}$ has been ended & $\begin{array}{l}\mathrm{C} \text { is a category, association type is } \\
\text { facta }\end{array}$ \\
\hline T8 & Knowledge Sharing & Knowledge $\mathrm{K}$ has been shared & $\begin{array}{l}\mathrm{K} \text { is a category, association type is } \\
\text { stata }\end{array}$ \\
\hline
\end{tabular}

In SIME and MIME scenarios wherein tacit knowledge is extracted from multiple experts, synthesis of knowledge is required and performed in transaction T5 (Knowledge Synthesis). Since it is critical to evaluate the quality of the extracted knowledge, evaluation is performed in transaction T6 
(Knowledge Evaluation). Lastly, the evaluated knowledge $\mathrm{K}$ is shared across the enterprise in transaction T8 (Knowledge Sharing). Overall, the eight transactions uniformly represent the lifecycle of the externalization process, describing what and how aspects of externalization.

\section{Interaction pattern (Who aspect)}

The interaction pattern depicts different actors involved in the externalization process and their interactions, as shown in Figure 3. The boundary of the diagram is represented as a "Socio-Technical Enterprise" which aligns with Nonaka's definition of "Ba" (Nonaka \& Konno, 1998), wherein Ba refers to a shared space for knowledge capture, in which the technical and cognitive skills of employees are captured through dialogue. Different actors involved in the externalization process include Case Requestor, Case Solver, Expert, Review Panel, Case Acceptor, and End User. The transactions defined in Table 2 are represented as interactions between the actors in the interaction pattern. The Case Requestor initiates the case for externalization of tacit knowledge with the Case Solver. The Case Solver refers to an intermediary employee in the enterprise or a system within the enterprise, which takes the case request from the Case Requestor and formulates the case, considering the case data (designated as bank B1) and available expert data (designated as bank B2) within the enterprise. Further, the Case Solver assigns the case to the experts and subsequently elicits their tacit knowledge to solve the case. Next, the Case Solver shares the elicited tacit knowledge with the Review Panel for synthesis and subsequent evaluation, which results in the explicit deliverable "case result" (designated as bank B3). Later, the Case Solver hands over the case result to the Case Acceptor who is interested in the outcome of the externalization process. Lastly, the Case Acceptor initiates the knowledge sharing activity, wherein the explicated knowledge is disbursed to the end-users of the enterprise.

Barring the Case Solver, who is always internal to the enterprise, all other actors can either be internal or external to the enterprise and are represented as A (for internal)/ CA (for external) in Figure 3.

Both transaction and interaction patterns are constructed using the DEMO (Design \& Engineering Methodology for Organizations) modelling software (ForMetis, 2016).

\section{MEASUREMENT VIEW}

The measurement view interlaces with the patterns described in the conceptual view and provides an approach to empirically measure the outcome of the externalization process.

The process of externalization can be modelled as a rule-based system of the form if < antecedent $>$ then < consequent>, wherein the "antecedent" part of the rule denotes the case that needs to be solved and the "consequent" part of the rule signifies the possible solution. Of course, a given antecedent can have multiple consequents wherein each consequent represents the externalized tacit knowledge of the experts and is of the form:

$$
\begin{array}{r}
\text { if }<\text { antecedent } \text { } \\
\text { then }<\text { consequent }_{1}>; \\
\text { then }<\text { consequent }_{2}>; \\
\ldots \text { then }<\text { consequent }_{n}>;
\end{array}
$$

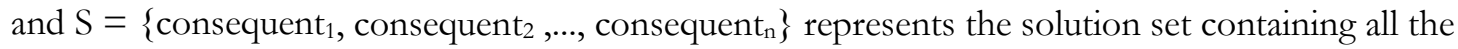
possible solutions. 


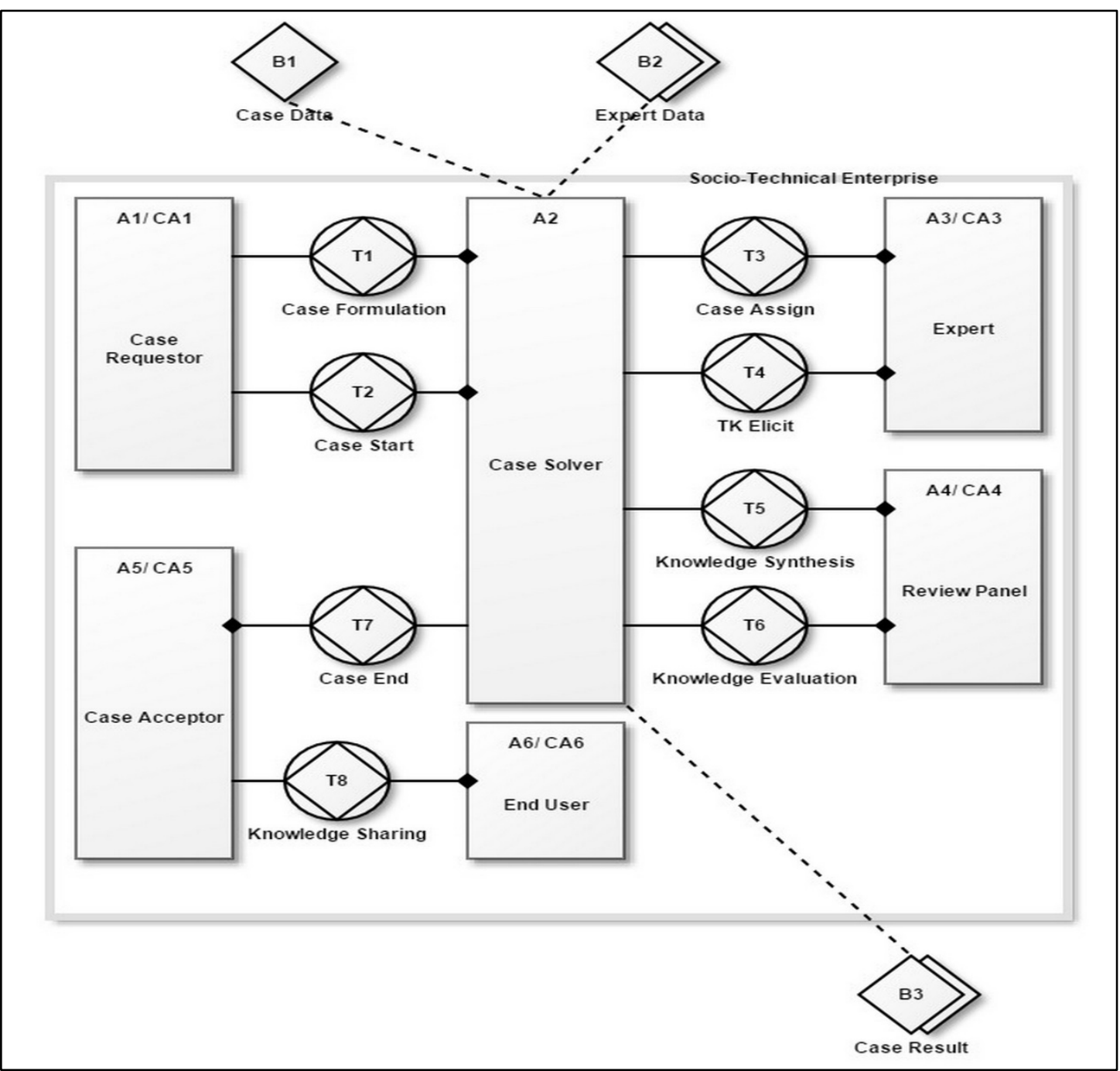

Figure 3. Interaction Pattern

We employ the certainty-factor model to measure the outcome of the externalization process, since the certainty-factor model is deemed efficient in managing uncertainty in rule-based systems (Heckerman, 1992; Ocegueda-Miramontes \& Juarez-Ramirez, 2013). In the externalization process, the term "uncertainty" refers to the uncertain outcome of the overall process of solving the case, which is a result of the individual expert's thoughts and actions during TK Elicit transaction, as well as the collective expert participation during the Knowledge Synthesis and Knowledge Evaluation transactions. In the following, we explain the measurement view by mapping the activities within each transaction (depicted in Table 2), with the concept of certainty-factor model.

\section{Case formulation transaction}

Let ' $\mathrm{C}_{1}$ ' represent the case which requires tacit knowledge externalization, identified by the Case Requestor. The case may belong to one of the following categories: decision making, problem solving, experience sharing, or business innovation. 


\section{Case assign transaction}

Let $E_{1}, E_{2}, \ldots, E_{n}$ represent the ' $n$ ' experts who are assigned to solve the case $C_{1}$. The statement holds true for SIME and MIME scenarios wherein tacit knowledge needs to be elicited from multiple experts. However, in SISE and MISE scenarios, the case is assigned to a single expert $\mathrm{E}_{1}$.

\section{TK elicit transaction}

Let $\mathrm{O}_{1}, \mathrm{O}_{2}, \ldots, \mathrm{O}_{j}$ represent the ' $\mathrm{j}$ ' opinions expressed by ' $\mathrm{n}$ ' experts during the TK Elicit transaction, wherein $\mathrm{j} \geq \mathrm{n}$. We have used a general term "opinion" to indicate the response of the expert that helps in solving the case. In reality, opinion represents a solution in a problem solving scenario, a decision in a decision making scenario, and an idea in a business innovation scenario. The opinions are represented as a rule of the form:

Rule: if $<$ Case $>$ then $<$ Opinion $>$;

Example: $\mathrm{R}_{1}$ : if $\mathrm{C}_{1}$ then $\mathrm{O}_{1}$ by $\mathrm{E}_{1}$;

$$
\begin{aligned}
& \text { then } \mathrm{O}_{2} \text { by } \mathrm{E}_{2} \text {; } \\
& \text {... then } \mathrm{O}_{\mathrm{j}} \text { by } \mathrm{E}_{\mathrm{n}} ;
\end{aligned}
$$

Here $\mathrm{C}_{1}$ represents the case to be solved and $\mathrm{S}=\left\{\mathrm{O}_{1}, \mathrm{O}_{2}, \ldots, \mathrm{O}_{\mathrm{j}}\right\}$ represents the solution set, which contains the externalized expert opinions for the case.

\section{Knowledge synthesis transaction}

The Review Panel vote for the opinions. Subsequently, the belief and disbelief measures, denoted as $M B$ and $M D$, are calculated for any opinion $\mathrm{O} j$ as follows:

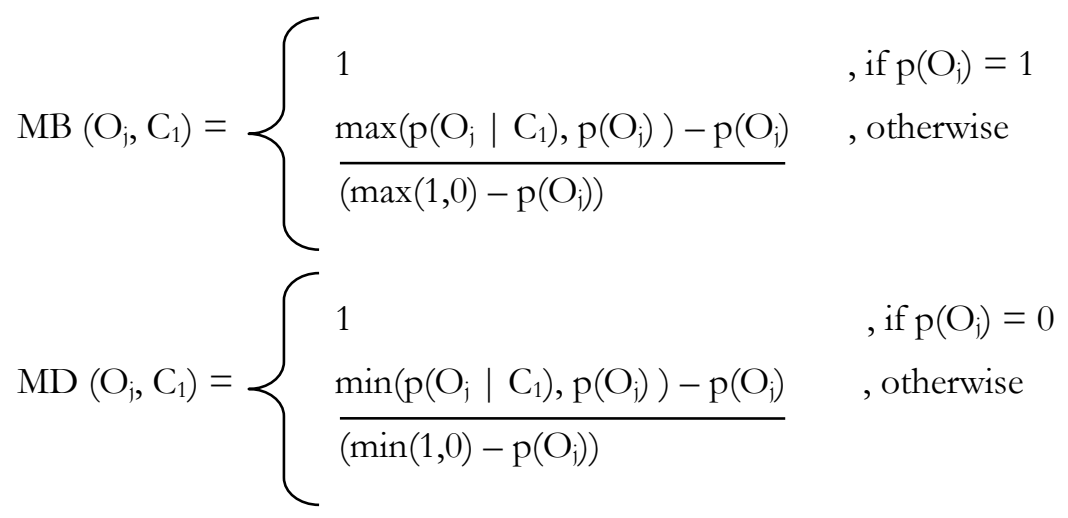

Here $\mathrm{p}\left(\mathrm{O}_{\mathrm{j}}\right)$ is the probability of $\mathrm{O} j$ being the solution for $\mathrm{C}_{1}$ expressed by the expert who opined $\mathrm{O} j$. The term $\mathrm{p}\left(\mathrm{Oj} \mid \mathrm{C}_{1}\right)$ represents the conditional probability of $\mathrm{Oj}$ being the solution for $\mathrm{C}_{1}$ expressed collectively by the Review Panel who voted for the opinion. A higher belief value towards +1.0 indicates positive validation for the opinion $\mathrm{Oj}$, while values close to zero indicate negative validation.

\section{Knowledge evaluation transaction}

The Review Panel calculates the Certainty Factors (CF) for every opinion. The CF for the opinion $\mathrm{Oj}$ is calculated as follows:

$$
\mathrm{CF}=\frac{\mathrm{MB}\left(\mathrm{Oj}, \mathrm{C}_{1}\right)-\mathrm{MD}\left(\mathrm{Oj}, \mathrm{C}_{1}\right)}{1-\min \left(\mathrm{MB}\left(\mathrm{Oj}, \mathrm{C}_{1}\right), \mathrm{MD}\left(\mathrm{Oj}, \mathrm{C}_{1}\right)\right)}
$$

The value of $\mathrm{CF}$ for an opinion $\mathrm{O} j$ reflects two things: (a) a collective degree of belief of the Review Panel in the opinion being a solution for the case; (b) a validation on the authenticity of the ex- 
pressed opinion, in terms of its business feasibility, economic viability, time to market, value proposition, etc. The Review Panel evaluates each opinion based on the CF value and identifies the best, average, and worst opinions elicited to solve the case $C_{1}$. The Review Panel refers to Table 3 to evaluate the $\mathrm{CF}$ values. As per Table 3, opinions with $\mathrm{CF}$ values between +0.6 to +1.0 are most viable and can be considered as potential solutions for $\mathrm{C}_{1}$. Opinions with $\mathrm{CF}$ values between +0.2 to +0.4 form the next set of viable solutions. However, opinions with $\mathrm{CF}$ values less than +0.2 indicates uncertainty and requires further solicitation of opinions to resolve $C_{1}$.

A key activity during the Knowledge Evaluation transaction is the generation of knowledge constructs or themes, which represent categories in which the evaluated opinions can be classified. During evaluation of opinions, the Review Panel identifies the knowledge constructs and places the opinions within the respective constructs. The knowledge constructs substantiate the collective wisdom of the experts involved in solving the given case. Lastly, the knowledge constructs along with the individual opinions are shared with the Case Acceptor, who decides on the appropriate solution that solves the case.

Table 3. Certainty-Factor with Term Descriptions (Ocegueda-Miramontes \& Juarez-Ramirez, 2013)

\begin{tabular}{|l|l|}
\hline TERM DESCRIPTION & CERTAINTY-FACTOR \\
\hline Definitely Not & -1.0 \\
\hline Almost Certainly Not & -0.8 \\
\hline Probably Not & -0.6 \\
\hline Maybe Not & -0.4 \\
\hline Unknown & -0.2 to +0.2 \\
\hline Maybe & +0.4 \\
\hline Probably & +0.6 \\
\hline Almost Certainly & +0.8 \\
\hline Definitely & +1.0 \\
\hline
\end{tabular}

\section{Knowledge sharing transaction}

This transaction helps in the dissemination of the externalized knowledge in the enterprise by storing the case details in a knowledge base. The rules generated for solving the case are also stored in the knowledge base.

\section{METHODOLOGY}

The EO model has been designed as a Web application titled ExtApp using Microsoft .NET 4.5 framework. The transactions within the EO model have been implemented using Microsoft Windows Workflow Foundation (WWF). Since WWF follows sequential execution model, each step in the transaction is modelled as an activity. An activity.xaml file contains the orchestration sequence for different transactions. As depicted in the class diagram, shown in Figure 4, the Activity class invokes the activity.xaml orchestration sequences through the InvokeXaml method. Most of the classes in the class diagram inherit from the BasePage class, which follows the front controller design pattern and provides a single point of contact for invoking the activity.xaml workflow. The classes Login, Case, User, Opinion, Voting, Email, and Result implement all the key functionalities of the EO model. The DBTransaction class contains methods for database transactions. SQL Server Compact edition is used as the enterprise knowledge base for storing the case details. 
Flyvbjerg (2006) argues that "One can often generalize on the basis of a single case, and the case study may be central to scientific development via generalization as supplement or alternative to other methods." Accordingly, we have used a "banking case" to generalize and demonstrate the applicability of the EO model for tacit knowledge externalization.

Financial Inclusion (FI) is a niche area in banking which is defined by Chakraborty as "The process of ensuring access to appropriate financial products and services needed by all sections of society, particularly the vulnerable groups such as weaker sections and low income groups at an affordable cost in a fair and transparent manner by mainstream institutional players" (Singh et al., 2014). Although banks implement abundant social welfare programs to help the poor financially, as part of financial inclusion, it is observed that middlemen's interference and time lag in reaching the benefits of the programs are the two most important factors plaguing the programs. The study focused on obtaining solutions to address these two problems from the tacit experience of experts in financial inclusion domain.

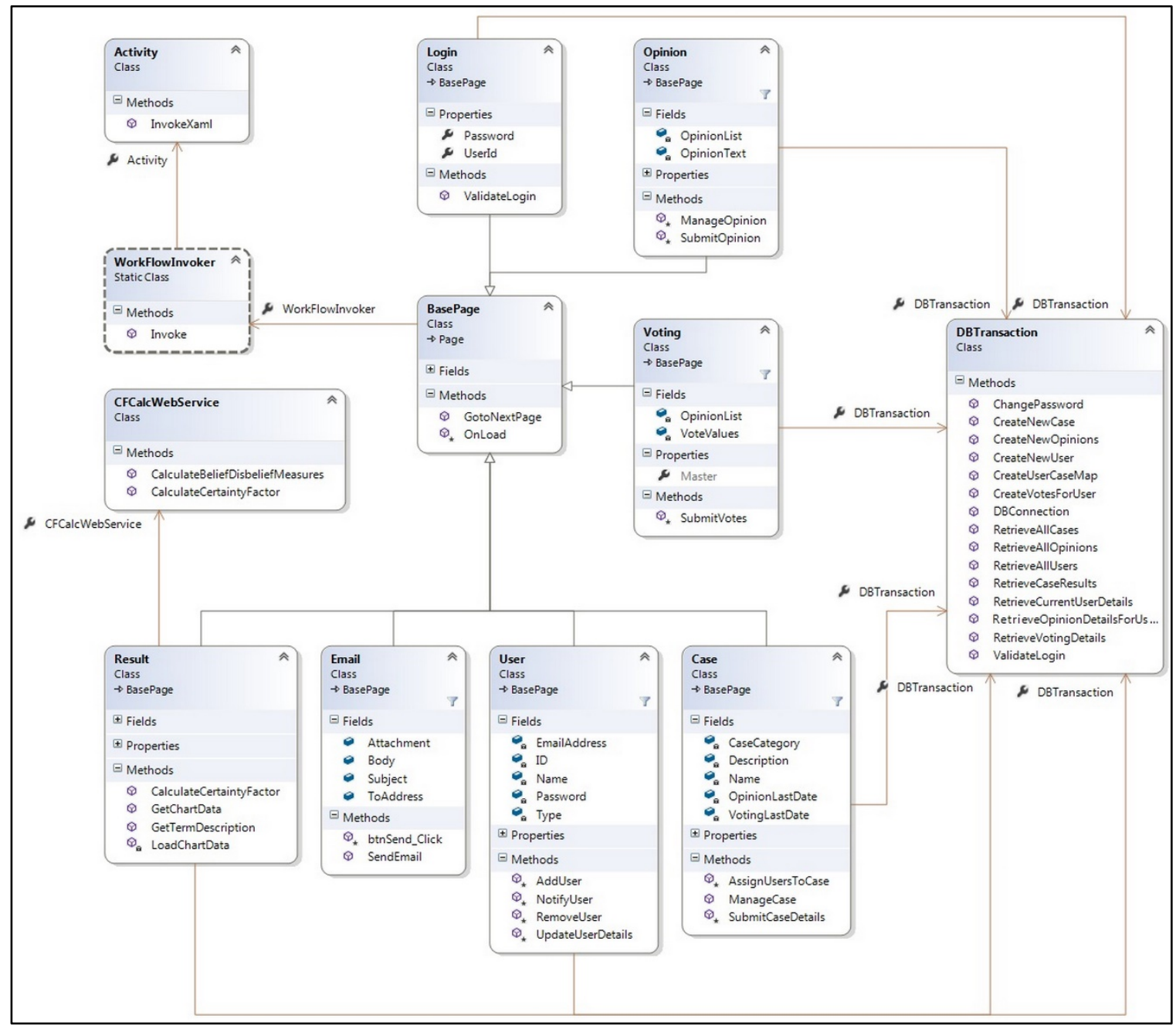

Figure 4. ExtApp Class Diagram

The beneficiaries of the financial inclusion programs are mainly the rural population, who are catered generally by the semi-urban and rural banks. Hence, in order to carry out the case study, two semi-urban nationalized banks (designated as B1 and B2) and two rural nationalized banks (designated as B3 and B4) were chosen, since these banks offer exclusive FI programs. Sample characteristics of the case are depicted in Table 4. The experts from these banks were chosen using simple random sampling technique. Since the branch managers interact with the rural population on a daily basis, 
they are aware of the problems faced by the people due to middlemen's interference and time lag in reaching the benefits of social welfare programs. Hence, the branch managers were chosen as "experts" to provide worthwhile solutions. In addition, two lead district managers from B2 and B3 banks were also assigned as experts, because of their vast tacit knowledge. The review panel comprised of four experts having designations as deputy manager and general manager, since they are more conversant with the latest banking policies, procedures, and government initiatives. Selecting the possible solutions to the cases not only requires tacit experience, but also appropriate knowledge of the binding policies and procedures required to validate the expert solutions. The average age of the expert was 38 years, and that of the review panel member was 51 years.

Table 4. Sample characteristics of the case

\begin{tabular}{|l|l|l|l|l|}
\hline ROLE & $\begin{array}{l}\text { PROFILE/ } \\
\text { DESIGNATION }\end{array}$ & $\begin{array}{l}\text { POPULA- } \\
\text { TION } \\
\text { COUNT }\end{array}$ & $\begin{array}{l}\text { SAMPLE } \\
\text { COUNT }\end{array}$ & $\begin{array}{l}\text { BANK REPRESENTA- } \\
\text { TION OF SAMPLES } \\
\text { WITH <B1, B2, B3, B4> } \\
\text { DESIGNATED AS } \\
\text { BANKS }\end{array}$ \\
\hline Case Requestor & Deputy Manager & 1 & 1 & B1 \\
\hline Case Solver & Operations Officer & 2 & 1 & B1 \\
\hline Expert & Branch Manager & 13 & 8 & $\begin{array}{l}\text { 2 each from B1, B2, B3, and } \\
\text { B4 }\end{array}$ \\
\cline { 2 - 5 } & Lead District Manager & 3 & 2 & B2 and B3 \\
\hline $\begin{array}{l}\text { Review Panel } \\
\text { Member }\end{array}$ & Deputy Manager & 5 & 3 & B1, B2, and B4 \\
\cline { 2 - 3 } & General Manager & 1 & 1 & B3 \\
\hline
\end{tabular}

\section{FINDINGS}

The case study demonstrates the applicability of the EO model in externalizing the tacit knowledge of experts to solve cases in financial inclusion domain. In the following, we describe the case findings, transaction-wise, according to the EO model.

\section{CASE FORMULATION TRANSACTION}

The Case Requestor provided two cases, namely:

C1: "Opinions to mitigate the time lag in reaching the benefits of social welfare programs to the ultimate beneficiary" and

C2: "Opinions to eliminate middlemen in transferring the benefits of social welfare programs to the ultimate beneficiary".

Both cases C1 and C2 belonged to the "problem solving" category of tacit knowledge externalization and demanded a SIME (Single Initiator Multiple Executor) scenario for externalization. As part of this transaction, the Case Solver, an Operations Officer who coordinated the externalization process, identified experts from four nationalized banks (B1-B4) to solve the two cases, in their personal capacity. Next, the Case Solver shared the case details with the experts through emails. A time frame of 10 days was provided for the experts to provide their opinions on the two cases, based on their tacit experience.

The ExtApp application was used by the Case Solver for entering the case details, assignment of the case to experts, and sending a notification to experts via email. The Case Solver also configured the 
minimum number of opinions per case, the maximum number of opinions per case, the minimum number of opinions per expert, the maximum number of opinions per expert, and size of the expert panel for opinion evaluation.

\section{TKELICIT TRANSACTION}

Each expert provided his opinion(s) on the case, based on his tacit experiences and skills. Totally, the experts gave 14 opinions for the first case, and 12 for the second. Sample data extracts of the opinions for both the cases are provided in the following.

\section{Case 1: Opinions to mitigate the time lag in reaching of benefits}

Although the Government devises multiple social welfare schemes as part of Financial Inclusion, it is evident that the "time lag" in reaching of the benefits to the end beneficiary is a major area of concern (Singh et al., 2014). Hence, the experts provided opinions to address the time lag problem from both the demand side as well as the supply side. The demand side represents the rural population seeking the schemes, while the supply side represents the Government which sanctions the various schemes. Out of the 14 opinions provided for the first case, 3 opinions $(21.42 \%)$ emphasized the need for exclusive changes on the demand side, 5 opinions (35.71\%) for exclusive changes on the supply side, and 6 opinions (42.85\%) recommended changes on both the sides. In the following, sample expert opinions (experts designated as Expert 1, Expert 2, and Expert 3) are provided wherein Expert 1 gave an opinion to correct the demand side, Expert 2 to correct the supply side, and Expert 3 to correct both the demand and supply sides.

From the demand side (representing the rural population), Expert 1 observed that non-opening of bank accounts by the beneficiaries is the single most cause of delay in reaching the monetary benefits of the schemes, and opined that "With the evolution of payment system in the country, the time lag from the date of remittance to credit to the ultimate beneficiary requires opening of Bank account for the beneficiary in a Bank. The Branch of the Bank in which beneficiary's account is opened needs to be a participant of the Payment System with products like IMPS (Immediate Payment System) of NPCI (National Payment Corporation of India). IMPS being operational on $24 X 7$ and 365 days basis, the transfer of social welfare benefits will be instantaneous".

From the supply side (representing the Government), Expert 2 observed that the date of commencement of any welfare scheme is very critical in preventing time lag, and hence opined that "Start any scheme before the commencement of the new year. All approvals/sponsoring applications to the bank must be over by August. Subsidy amount must be released well before sponsoring the application".

According to Expert 3, identifying the beneficiaries for welfare schemes is a very time consuming process which induces a significant delay in reaching of the benefits. To speed up this process, Expert 3 opined that "There should be a task. force committee consisting of District Administrator, Lead Bank Manager, and concerned Government departments to identify the deserving beneficiaries. This committee should provide wide publicity to popularize the social welfare schemes explaining their benefits to the common man, before launching".

Furthermore, Expert 3 observed that the rural population needs financial literacy in order to mitigate the time lag and advocated that "Services of financial literacy centers may be utilized to spread financial literacy in the areas".

\section{Case 2: Opinions to eliminate middlemen}

In the banking context, the term "middleman" refers to people who act as agents between the bank and its customers (rural or semi-urban people in this context). Since a majority of the rural bank customers are illiterates in the Indian context, the middlemen offer them help in availing the benefits of financial inclusion schemes, in exchange for a commission or a fee. Hence, eliminating these middlemen is the need of the hour.

Expert 4 observed that a majority of the middlemen are Government employees or bank employees. Hence, in order to eliminate middlemen, Expert 4 opined that "the task can be maximized if there are 
strong-willed personnel in all Government departments and banks who refuse to budge to external pressure. This personnel should be motivated in the right direction and also given moral support by their controlling officers as well as local administrative bodies". The opinion emphasized the need for creating awareness and imparting training to the employees in banks and Government departments.

Expert 5 further observed that officers in Government departments act as middlemen if their tenure is longer. Hence, in order to eliminate middlemen, Expert 5 opined that "All officers in Government departments must be transferred once in 3-5 years to prevent corruption and bribery. And they should not be deputed back to the same place ever". In order to prevent bribery in the Government departments, Expert 5 elaborated that "Banks must recruit "Helpers" to help the illiterates to fill up application forms who report to the bank manager. This prevents bribery from village helpers who take bribe for helping illiterates to fill up forms/ schemes".

While Experts 4 and 5 framed their opinions from the middlemen's perspective, Expert 6 framed his opinion from the bank customer's perspective. He perceived that opening bank accounts through the EBS (E-Billing Solution) system was sufficient to eliminate middlemen and opined that "All the clients claiming social benefits such as Pension, Government Aid, and other facilities provided by various departments such as education, Forest, SC/ST Corporation have to open bank accounts in commercial banks where EBS system is available. Benefits go to the beneficiaries' accounts by EBT mode and middlemen are avoided. Delay is also avoided'.

Overall, the majority of the experts were of the opinion that eliminating these middlemen altogether may be a "herculean task".

\section{KNOWLEDGE SYNTHESIS TRANSACTION}

In order to synthesize the opinions and arrive at meaningful conclusions to solve the cases, a review panel consisting of 4 senior experts in "financial inclusion" domain was formed, whose profile is mentioned in Table 4. The review panel brainstormed possible ways to rate the opinions provided by the experts. They finalized business feasibility, economic viability, and time to market as the key factors for rating the opinions. The business feasibility factor mandates the opinion to be pragmatic and gel well with the existing policies and procedures laid out by the State and Central Governments. The economic viability factor considers the financial investment required to actualize the opinion in terms of cost and effort. Lastly, the time to market factor considers the operational and technological aspects, since technology is the driving force to effectively implement the opinions.

Subsequently, the review panel members voted the experts' opinions based on business feasibility, economic viability, and time to market factors on a scale of 1-10.

\section{KNOWLEDGE EVALUATION TRANSACTION}

In this transaction, the review panel performed two activities: (a) evaluation of the opinions, and (b) generation of knowledge constructs. The review panel evaluated the opinions by calculating the belief measure, disbelief measure, and finally, the certainty factor for each opinion through the ExtApp application, as shown in Figure 5. In Figure 5, the term description "Almost certainly" indicates that the opinion expressed by the expert is the most viable solution, business and economy wise, and can be considered as a potential solution for the case by the review panel. The term descriptions "Probably" and "Maybe" indicate the next best opinions which can be considered, in that order. The term description "Unknown" indicates uncertainty and refers to an open area where more opinions need to be solicited.

\section{Generation of knowledge constructs (themes):}

In order to generate the knowledge constructs, the review panel first analyzed the solutions having favorable CF values. They observed that some solutions indicated long-term changes, while others indicated short-term changes. Long-term solutions involved changes in policy, operational aspects, and spreading awareness among the people regarding the social welfare programs. In contrast, shortterm solutions involved technology changes and training of the bank employees. 
Overall, based on these observations, the review panel categorized the opinions into four main knowledge constructs or themes, namely, (a) Awareness and social change; (b) IT enablement; (c) Policy change \& operational aspect; and (d) Training \& resource management in banks. While the constructs (a) and (c) indicate long-term solutions to solve the cases, the construct (b) indicates a medium-term solution involving technology changes, and the construct (d) represents a short-term solution, which can be operationalized on an immediate basis.

The knowledge constructs substantiate the collective wisdom of the experts in solving the cases so that future cases of the similar type can reuse this collective knowledge.

\begin{tabular}{|c|c|c|c|}
\hline \multicolumn{2}{|r|}{ Login User Role: Case Acceptor } & \multicolumn{2}{|c|}{ Logout } \\
\hline \multicolumn{4}{|c|}{ Suggest Opinions to eliminate middlemen in transfering the benefits of social welfare programs } \\
\hline \multicolumn{4}{|c|}{ View Results } \\
\hline \multicolumn{4}{|c|}{ Certainty Factors with Term Descriptions } \\
\hline $\begin{array}{l}\text { Opinion } \\
\text { Id }\end{array}$ & Opinion & $\begin{array}{l}\text { Certainty } \\
\text { Factor }\end{array}$ & $\begin{array}{c}\text { Term } \\
\text { Description }\end{array}$ \\
\hline 1 & $\begin{array}{l}\text { The District Authorities who identify the beneficiaries, can ensure enrolment of the } \\
\text { beneficiaries to AADHAR of UIDAI. The Bank Account number to be linked to AADHAR Number }\end{array}$ & 0.74 & Probably \\
\hline 2 & $\begin{array}{l}\text { For MNREGA scheme, the amounts not going directly to bank accounts of ultimate } \\
\text { beneficiaries, paying cheques as "Account Payee" is the solution. }\end{array}$ & 0.2 & Unknown \\
\hline 3 & $\begin{array}{l}\text { Politicians should be only policy makers and not interfere in schemes. Reduce the number of } \\
\text { review meetings with politicians. Discuss only on furnished data in the meetings. Adequate } \\
\text { staff and recruitment in Government offices. }\end{array}$ & 0.66 & Probably \\
\hline 4 & $\begin{array}{l}\text { All officers in Government departments must be transferred once in } 3-5 \text { years to prevent } \\
\text { corruption and bribery. And they should not be deputed back to the same place ever. Banks } \\
\text { must recruit "Helpers" to help the illiterates to fill up application forms who report }\end{array}$ & 0.2 & Unknown \\
\hline 5 & $\begin{array}{l}\text { DBT - Direct Bank Transfer for gas subsidy, widow pension, minority schemes etc. Already } 60 \text { - } \\
65 \% \text { of the middlemen are eliminated. Create awareness in social welfare schemes and benefits } \\
\text { to illeterate farmers, generally full schemes are not understood by }\end{array}$ & 0.4 & Maybe \\
\hline 6 & $\begin{array}{l}\text { To change attitude of people towards banking concepts in order to translate knowledge into } \\
\text { behavior }\end{array}$ & 0.2 & Unknown \\
\hline 7 & $\begin{array}{l}\text { IMPS being operational on } 24 \times 7 \text { and } 365 \text { days basis, the elimination of middlemen will be } \\
\text { instantaneous }\end{array}$ & 0.4 & Maybe \\
\hline
\end{tabular}

Figure 5. Screenshot of ExtApp displaying CFs for Case 2

\section{KNOWLEDGE SHARING TRANSACTION}

Lastly, as part of the Knowledge Sharing transaction, the Case Solver generated various charts and graphs, as depicted in Figures 6, 7, and 8. Figure 6 showcases pie charts which depict certainty factor distributions for cases 1 and 2 .

From the review panel perspective, tacit knowledge externalization for case 1 is more successful than case 2. Case 1 has higher percentages for the term descriptions "Almost certainly (14.29\%)", "Probably (21.43\%)", and "Maybe (28.57\%)" compared with case 2 and more importantly, a much lower "Unknown (35.71\%)" value, which indicates that the review panel has collectively accepted the solutions for case 1 more than case 2. From the experts' perspective, the CF distributions for cases 1 and 2 indicate that the expert's tacit knowledge in solving case 1 is more profound than case 2 , and probably case 2 needs TK externalization from more experts for arriving at productive solutions. 


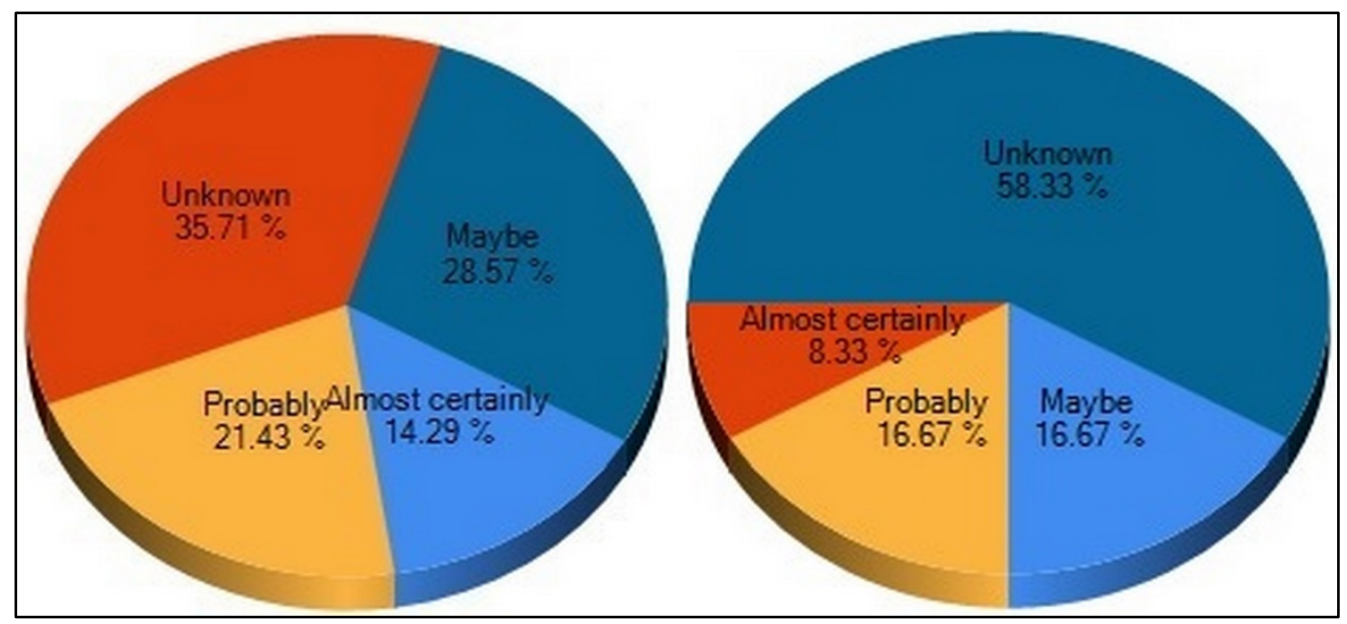

Figure 6. Charts depicting CF distributions for Case 1 and Case 2

Figure 7 depicts user-wise CF distribution for case 2. The chart helps in identifying the distribution of highest contributing experts to lowest contributing experts for a particular case. In case 2, user 6 is the highest contributor with a CF value of 0.8 , indicating the highest probability that his/her solution will be accepted, as judged by the review panel. Furthermore, users 9 and 10 are the lowest contributors towards solving case 2 .

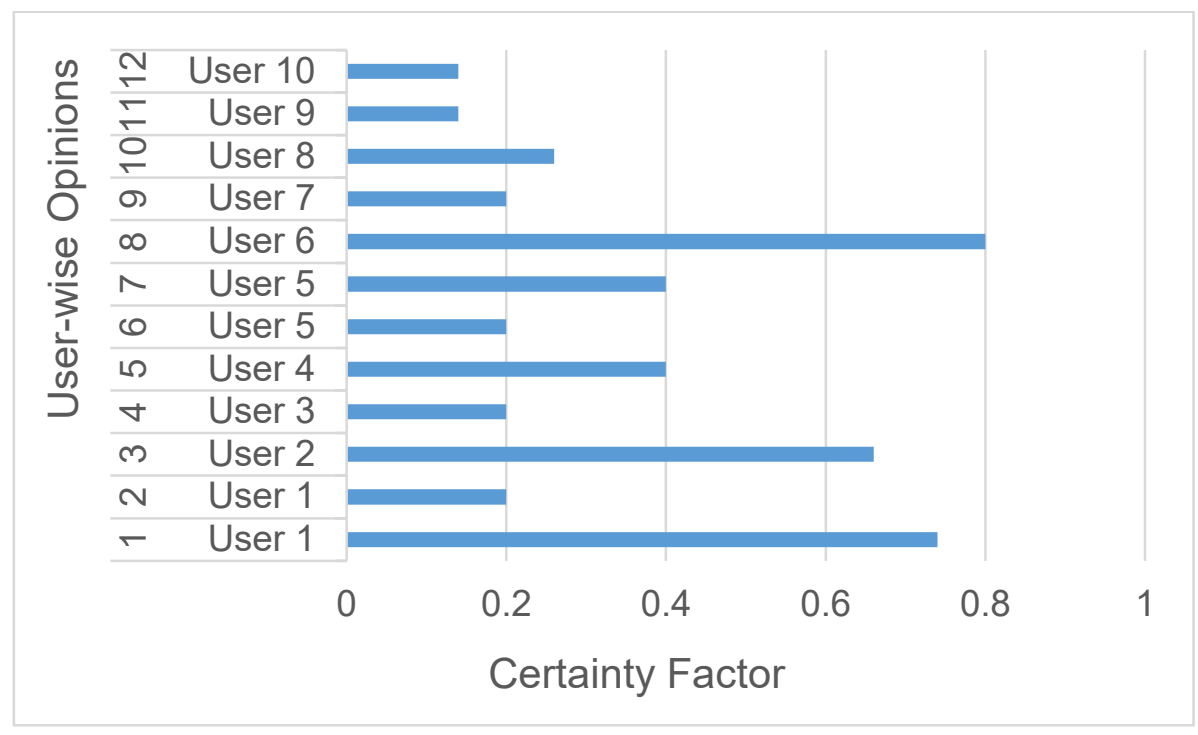

Figure 7. Chart depicting user-wise CF distribution for Case 2

Figure 8 depicts the count of CF term descriptions per knowledge construct for case 2 . The chart helps the Case Acceptor to ascertain which knowledge construct is most useful in solving the case. For example in solving case 2, the knowledge construct "IT enablement" is the best option for the Case Acceptor, since the construct contains the opinions with CF term descriptions as "Almost certainly" and "Probably". 


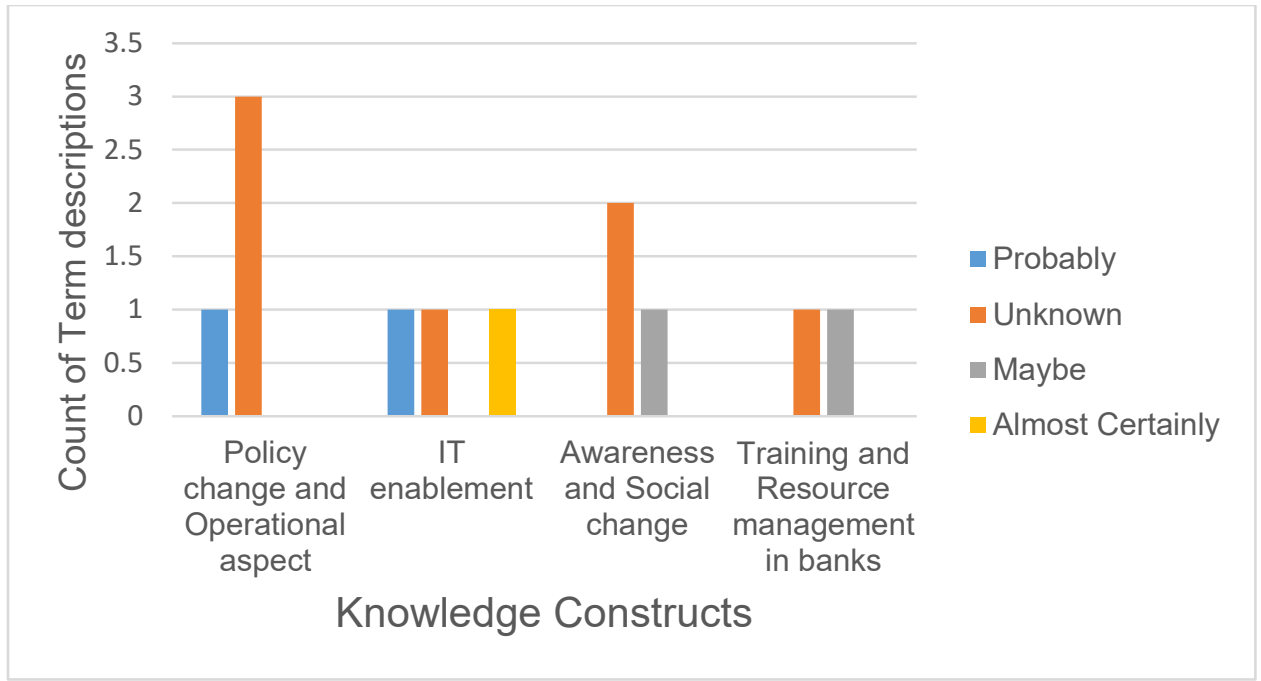

Figure 8. Chart depicting count of CF term descriptions per knowledge construct for Case 2

Overall, the two case details are stored in the SQL Server Compact database, which acts as the enterprise knowledge base. The case details comprise of case descriptions, case configurations, expert assignments to the case, and case results. The case details can be reused for any similar externalization scenario occurring in the enterprise.

\section{DisCussion}

This section describes how the EO model integrates diverse aspects of externalization and its applicability in various externalization scenarios.

The overall research contribution is summarized in Figure 9. While the transaction pattern generalizes the scenarios of externalization (when aspect), the extended transaction pattern builds on the transaction pattern and generalizes the lifecycle (what aspect) and methods (bow aspect) of externalization respectively. Furthermore, the interaction pattern generalizes the actor interaction aspect of externalization (who aspect) by adding actor interactions to the identified transactions from the extended transaction pattern. The certainty-factor model maps with the transactions and actors defined in the interaction pattern and provides a measurement of the outcome of the externalization process. Thus, the combination of conceptual view and measurement view integrates diverse aspects of externalization, as depicted in Figure 9. The implementation of the EO model through the ExtApp application, along with the case study, further validate this integration.

Overall, the research contribution can be utilized in the following ways: (a) The proposed patterns serve as a template that can be easily customized for any future scenarios in externalization; (b) Although the EO model is demonstrated for a problem solving scenario in a banking environment, the model is generic and can be replicated for any decision making, knowledge sharing, and business innovation activities that involve externalization in socio-technical enterprises. To further illustrate the point (b), we discuss the application of the EO model in other real-world externalization scenarios in the following. 


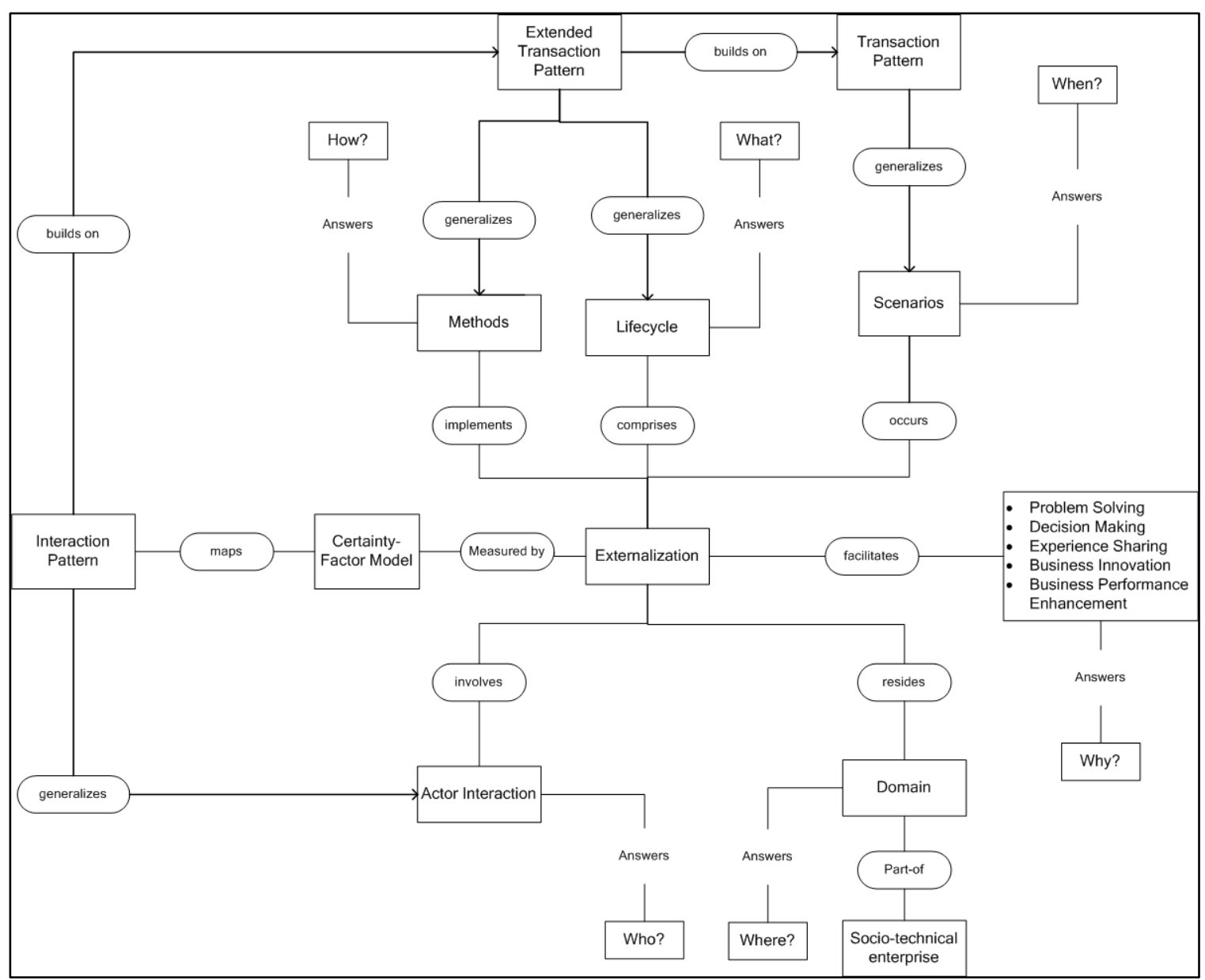

Figure 9. Overview of the research contribution

\section{CAPTURE-WHILE-DOING SCENARIO}

Martinho and Silva (2012) proposed a non-intrusive way of eliciting tacit knowledge from end-users in the enterprise through a capture-while-doing strategy, depicted in Figure 10.A. Their strategy proposes an ad hoc, people-driven workflow for tacit knowledge capture, wherein end-users of the enterprise interact with one another through a request-response mechanism and share their tacit knowledge, while continuing with their regular work. As shown in Figure 10.A, the end-user R1 owns two data objects named D1 and D2, which represents his/her tacit knowledge. Further, R1 is interested to accomplish an enterprise goal, for which he/she needs the tacit knowledge possessed by end-user R2. Accordingly, R1 initiates a request named $A$ to $\mathrm{R} 2$, providing D1 as input. Next, $\mathrm{R} 2$ realizes that his/her tacit knowledge D3 is insufficient to accomplish the enterprise goal provided by R1 and initiates a request $B$ to end-user $\mathrm{R} 3$ to participate in fulfilling the goal. Lastly, R2, after receiving the data object D4 from R3, replies with an updated version of D1, D3, and D4 to end-user R1.

The EO model is well suited to capture such ad hoc, people-driven externalization scenarios and represent their interactions through the interaction pattern demonstrated in Figure 10.B. In the Figure, the end-user R1 represents the Case Requestor, who is interested to solve an enterprise goal termed as a "case". The Case Requestor R1 recognizes that the tacit knowledge of end-user R2 is required to solve the case and accordingly initiates the transactions T1, T2, and T3, thereby assigning the case to $\mathrm{R} 2$ with a request $\langle\mathrm{A}\rangle$. Also, R1 shares the data object D1 as case data with R2. Next, R2 reprises the role of an Expert and produces deliverable D3 through his/her tacit knowledge, which represents the TK Elicit transaction. Also, R2 reprises the role of Case Solver and sends D1 and D3 data 
as inputs to end-user R3, through T3 (Case Assign transaction) with request $<\mathrm{B}>$. R3 produces deliverable D4, as a result of TK Elicit transaction. Lastly, R2 synthesizes the deliverables D3 and D4 through Knowledge Synthesis transaction and returns the case result comprising an aggregate of D1, D3, and D4 deliverables, to the Case Acceptor R1 which signifies the solving of the case. Typically, the capture-while-doing scenarios are SIME type with a single case initiator and multiple executors. However, MIME (multiple initiators and multiple executors) types can also be adopted if we consider simultaneous realization of multiple goals within the enterprise.

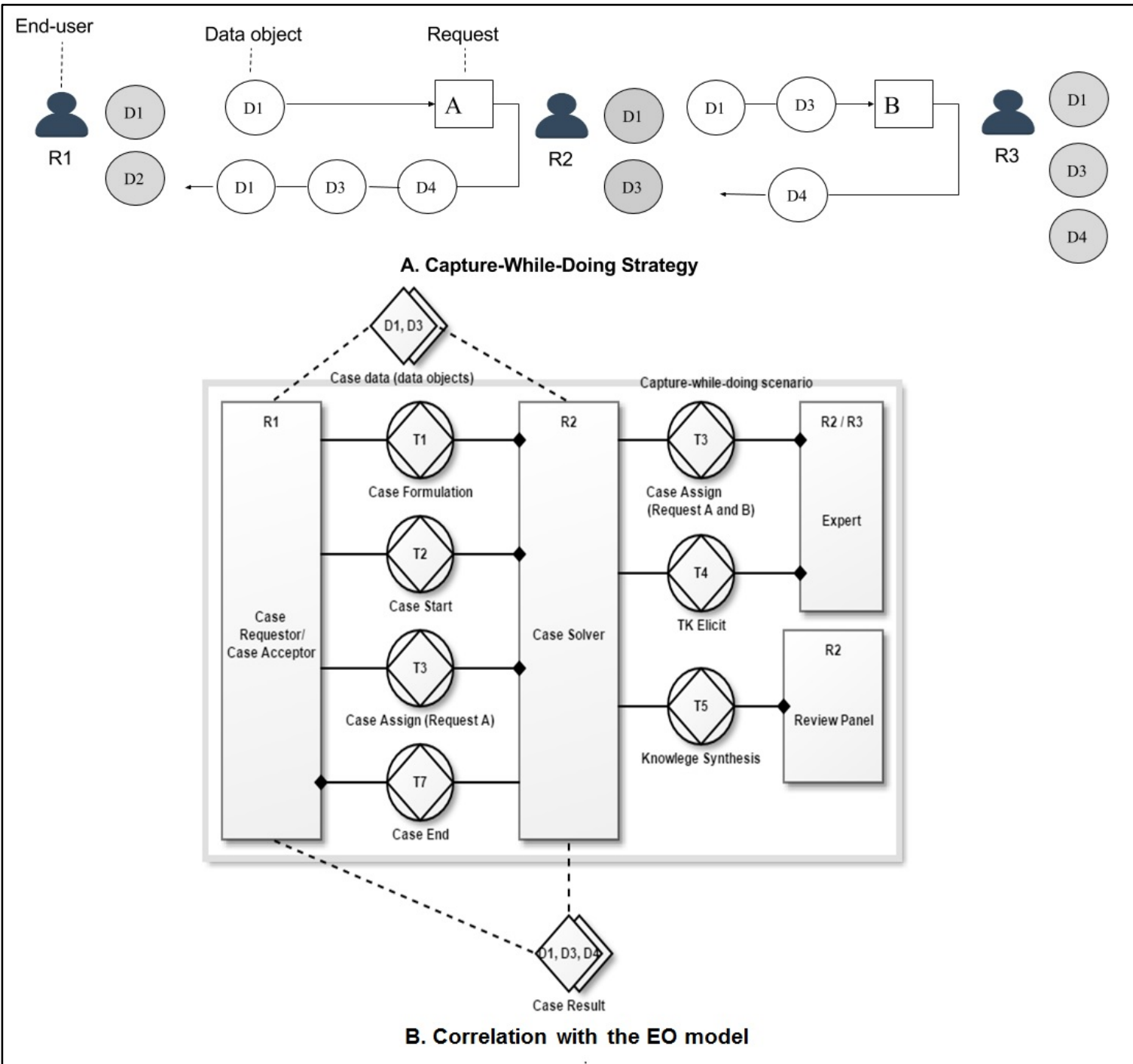

Figure 10. Capture-while-doing scenario

\section{OPEN INNOVATION SCENARIO - IDEA COMPETITION MODEL}

Open innovation refers to a model for organizing technological innovation in R\&D intensive sociotechnical enterprises (Anandarajan \& Akhilesh, 2013). Idea competition is a model of open innovation which aims to solicit maximum ideas from knowledge workers within the enterprise, to solve a specific problem. Anandarajan and Akhilesh (2013) state that "tacit knowledge" of the knowledge workers forms the key element in such competitions and the competitions serve as scenarios for tacit knowledge externalization. An example of idea competition is conducting an informal event hacka- 
thon, wherein developers across the world participate to solve specific problems ranging in areas such as operating systems, mobile applications, and Web development.

The EO model serves as an umbrella model, which accommodates "idea competition" as externalization process. First, in the Case Formulation transaction, the organizers of the idea competition formulate a specific problem (case) for which ideas need to be solicited. Second, the organizers identify experts and notify them of the idea competition. Third, the experts provide ideas (opinions / solutions) to solve the problem based on their tacit knowledge, which forms the TK Elicit transaction. In this activity, one can use any tacit knowledge elicitation method (Acosta et al., 2004; Al-Qdah \& Salim, 2013; Chatti et al., 2007; Ocegueda-Miramontes \& Juarez-Ramirez, 2013; Whyte \& Classen, 2012), for seeking potential ideas. Fourth, a group of experts form a review panel, synthesize the ideas and further validate their correctness. The synthesis and validation processes together represent the Knowledge Synthesis transaction. Fifth, the review panel evaluates the proposed ideas based on any evaluation technique, such as Delphi (Whyte \& Classen, 2012) or certainty factor evaluation (Ocegueda-Miramontes \& Juarez-Ramirez, 2013), which forms the Knowledge Evaluation transaction. Lastly, the best ideas that solve the problem are selected and informed to all the participants (end-users), which forms the Knowledge Sharing transaction.

\section{PROCESS-BASED EXTERNALIZATION SCENARIO}

The case study and open innovation scenarios demonstrate the application of the EO model in problem solving and business innovation respectively. To illustrate the applicability of the EO model in process-based scenarios, we consider the work of Andreasik (2007). Andreasik proposed a process-based externalization lifecycle comprising of retrieve, reuse, review, revise, and retain activities. Correlating with the EO model, first, Case Formulation transaction encompasses the "retrieve" process, wherein the formulation of a new case involves retrieval and referencing of similar cases from the knowledge repository. Second, the TK Elicit transaction encompasses the "reuse" process wherein reusing the solution of an existing case presents a possible elicitation method. Third, the Knowledge Synthesis transaction encompasses the "review" process for verification of the potential solution. Fourth, the Knowledge Evaluation transaction encompasses the "revise" process wherein the potential solution is evaluated and corrected, if required. Lastly, Knowledge Sharing transaction encompasses the "retain" process, wherein the solution for the identified case is stored in a repository for enterprise sharing.

The application of the EO model in various externalization scenarios demonstrates that the views (conceptual and measurement) are generic and reusable, providing a uniform representation of the externalization process.

\section{CONCLUSION AND FUTURE WORK}

In today's fast-changing enterprise environment, innovation and rapid decision-making form the key activities for business survival. An important factor that aids in performing these key activities is tacit knowledge externalization. The paper identifies different aspects of tacit knowledge externalization and integrates these aspects through the EO (Enterprise Ontology) model, which comprises conceptual and measurement views. The conceptual view comprises three patterns called transaction pattern, extended transaction pattern, and interaction pattern, which conceptually model the externalization process based on Enterprise Ontology concepts. The measurement view employs the certaintyfactor model to measure the outcome of the externalization process. The EO model is implemented as a Web application titled "ExtApp", measured using the certainty-factor model, and demonstrated via a banking-based case study.

There are two limitations of the EO model. The first limitation is that our approach caters to only individual and group externalization scenarios within an enterprise. Currently, we have not considered tacit knowledge externalization at the enterprise/organizational level. The second limitation is 
that our work caters to externalization scenarios involving human effort. We have not considered tacit knowledge externalization from systems within the enterprise.

We believe that this study contributes to knowledge management practice in enterprises, in the following ways. First, the study derives patterns for externalization, which can be applied to any operation in socio-technical enterprises that involves knowledge seekers and providers. Second, the study enhances the current understanding of tacit knowledge externalization, from the light of integrating diverse aspects on externalization, through the EO model.

We plan to extend the current research in three ways. First, the EO model shall be extended to include tacit knowledge externalization from partially automated enterprise systems. Second, the EO model shall be applied to other domains, possibly involving larger datasets of experts. Third, the ExtApp application shall be hosted on the cloud platform, thereby enabling any enterprise to reuse the application for externalization purposes.

\section{ACKNOWLEDGEMENTS}

The authors thank Mr Sathyanarayana Rao and Mr Anjan Kumar, DM, Canara Bank for providing the business cases for the banking case study and also thank all the participants of the case study.

\section{REFERENCES}

Acosta, C. E., Collazos, C. A., Guerrero, L. A., Pino, J. A., Neyem, H. A., \& Moteletm, O. (2004). StoryMapper: A multimedia tool to externalize knowledge. In Proceedings of the 24th International Conference of the Chilean Computer Science Society (SCCC) (p. 133-140). Arica, Chile.

Al-Qdah, M., \& Salim, J. (2013). A conceptual framework for managing tacit knowledge through ICT perspective. In Proceedings of the 4th International Conference on Electrical Engineering and Informatics, ICEEI (p. 11881194). Malaysia.

Aming'a, N. N. (2015). Knowledge capture and acquisition mechanisms at Kisii University. Interdisciplinary Journal of Information, Knowledge, and Management, 10, 105-116. Retrieved from https://www.informingscience.org/Publications/2284

Anandarajan, I., \& Akhilesh, K. B. (2013). Effective utilization of tacit knowledge in technology management. In C. Mukhopadhyay, R. Srinivasan, A. Gurtoo, \& P. Ramachandran (Eds.), Driving the economy through innovation and entrepreneurship (p. 461-471). Springer India: Springer.

Andreasik, J. (2007). A case-base reasoning system for predicting the economic situation of enterprises - tacit knowledge capture process (externalization). In M. Kurzynski \& E. Puchala (Eds.), Computer recognition systems (Vol. 2, p. 718-730). Berlin Heidelberg: Springer.

Booch, G. (2010). Enterprise architecture and technical architecture. IEEE Software, 27(2), 96.

Chandra, R., Iyer, R. S., \& Raman, R. (2015). Enabling organizations to implement smarter, customized social computing platforms by leveraging knowledge ow patterns. Journal of Knowledge Management, 19(1), 95-107.

Chatti, M. A., Klamma, R., Jarke, M., \& Naeve, A. (2007). The Web 2.0 driven SECI model based learning process. In Proceedings of the Seventh IEEE International Conference on Advanced Learning Technologies (ICALT) (p. 780-782). Niigata, Japan.

Choudrie, J., \& Selamat, M. H. (2006). The consideration of meta-abilities in tacit knowledge externalization and organizational learning. In Proceedings of the 39th Annual Hawaii International Conference on System Sciences (HICSS) (p. 149). Kauia, HI.

Dalkir, K. (2005). Knowledge management in theory and practice. United Kingdom: Butterworth-Heinemann.

Deloitte. (2015). Mind the gaps: The 2015 Deloitte millennial survey. Retrieved September 20, 2016, from https://www2.deloitte.com/content/dam/Deloitte/global/Documents/About-Deloitte/gx-wef-2015millennial-survey-executivesummary.pdf

Dietz, J. L. G. (2006). Enterprise ontology - Theory and methodology. Berlin Heidelberg: Springer. 
Dzekashu, W. G. (2015). Tacit knowledge capture: A quality management imperative for attainment of operational excellence. Bloomington, Indiana: Xlibris Corporation.

Echajari, L., \& Thomas, C. (2015). Learning from complex and heterogeneous experiences: The role of knowledge codification. Journal of Knowledge Management, 19(5), 968-986.

Erden, Z., von Krogh, G., \& Nonaka, I. (2008). The quality of group tacit knowledge. The Journal of Strategic Information Systems, 17(1), 4-18.

Flyvbjerg, B. (2006). Five misunderstandings about case-study research. Qualitative Inquiry, 12(2), 219-245.

ForMetis. (2016). Online modeling tool for process design and animation. Retrieved September 25, 2016, from https://www.demoworld.nl/Portal/Home

Friedrich, W. R., \& van der Poll, J. A. (2007). Towards a methodology to elicit tacit domain knowledge from users. Interdisciplinary Journal of Information, Knowledge, and Management, 2, 179-193. Retrieved from https://www.informingscience.org/Publications/108

Haron, H., Noordin, S. A., \& Alias, R. A. (2010). An interpretive exploration on tacit knowledge dimensions in academia. In Proceedings of the International Conference on Information Retrieval and Knowledge Management (CAMP) (p. 326-331). Shah Alam, Selangor.

Heckerman, D. (1992). The certainty-factor model. Encyclopedia of Artificial Intelligence.

Jackson, P. (2010). Capturing, structuring and maintaining knowledge: A social software approach. Industrial Management and Data Systems, 110(6), 908-929.

Jia, C., Cai, Y., Yu, Y. T., \& Tse, T. H. (2016). 5W+1H pattern: A perspective of systematic mapping studies and a case study on cloud software testing. Journal of Systems and Software, 116, 206-219.

Khan, A., \& Khader, S. A. (2014). An approach for externalization of expert tacit knowledge using a query management system in an e-learning environment. The International Review of Research in Open and Distributed Learning, 15(6), 257-274.

Kruchten, P. B. (1995). The 4+1 View Model of Architecture. IEEE Software, 12(6), 42-50.

Leonard, N., \& Insch, G. (2005). Tacit knowledge in academia: A proposed model and measurement scale. The Journal of Psychology: Interdisciplinary and Applied, 139(6), 495-512.

Li, G., \& Lu, K. (2007). A research study on externalization of tacit knowledge based on Web 2.0. In W. Wang, Y. Li, Z. Duan, L. Yan, H. Li, \& X. Yang (Eds.), Integration and Innovation Orient to E-Society (Vol. 252, p. 6067). US: Springer.

Martinho, D., \& Silva, A. R. (2012). A recommendation algorithm to capture end-users' tacit knowledge. In A. Barros, A. Gal, \& E. Kindler (Eds.), Business process management (Vol. 7481, p. 216-222). Berlin Heidelberg: Springer.

Munoz, C. A., Mosey, S., \& Binks, M. (2015). The tacit mystery: Reconciling different approaches to tacit knowledge. Knowledge Management Research and Practice, 13(3), 289-298.

Nonaka, I., \& Konno, N. (1998). The concept of 'Ba': Building a foundation for knowledge creation. California Management Review, 40(3), 40-54.

Nonaka, I., \& Takeuchi, H. (1995). The knowledge-creating company: How Japanese companies create the dynamics of innovation. United Kingdom: Oxford University Press.

Okafor, E. C., \& Osuagwu, C. C. (2006). The underlying issues in knowledge elicitation. Interdisciplinary Journal of Information, Knowledge, and Management, 1, 95-107. Retrieved from https://www.informingscience.org/Publications/116

Ocegueda-Miramontes, V., \& Juarez-Ramirez, R. (2013). Tacit knowledge formalization to support the adoption process of software quality models. In Z. Qin \& V.-N. Huynh (Eds.), Integrated uncertainty in knowledge modelling and decision making (Vol. 8032, p. 180-191). Berlin Heidelberg: Springer.

Pham, Q. T., \& Hara, Y. (2009). Combination of two KM strategies by Web 2.0. In D. Karagiannis \& Z. Jin (Eds.), Knowledge science, engineering and management (Vol. 5914, p. 322-334). Berlin Heidelberg: Springer. 
EO Model for Tacit Knowledge Externalization

Polanyi, M. (1966). The tacit dimension. London: Routledge and Kegan Paul.

Richards, D., \& Busch, P. (2003). Acquiring and applying contextualized tacit knowledge. Journal of Information and Knowledge Management, 2(2), 179-190.

Serrat, O. (2008). Notions of knowledge management. Retrieved August 5, 2016, from https://www.k4health.org/sites/default/files/Notions-Knowledge-Management.pdf

Sigala, M., \& Chalkiti, K. (2007). Improving performance through tacit knowledge externalization and utilization. International Journal of Productivity and Performance Management, 56(5), 456-483.

Singh, C., Mittal, A., Garg, R., Goenka, A., Goud, R. P., Ram, K., ... \& Kumar, U. (2014). Financial inclusion in India: Select issues. Working Paper No. 474. Retrieved December 26, 2016, from Indian Institute of Management, Bangalore website https://www.iimb.ernet.in/research/sites/default/files/WP\%20No.\%20474.pdf

Venkitachalam, K., \& Busch, P. (2012). Tacit knowledge: Review and possible research directions. Journal of Knowledge Management, 16(2), 357-372.

Whyte, G., \& Classen, S. (2012). Using storytelling to elicit tacit knowledge from SMEs. Journal of Knowledge Management, 16(6), 950-962.

Ye, N., \& Zhi-ping, F. (2006). An empirical study on the context of tacit knowledge transfer in knowledge alliances. In Proceedings of the International Conference on Service Systems and Service Management (p. 178-183). Troyes.

\section{BIOGRAPHIES}

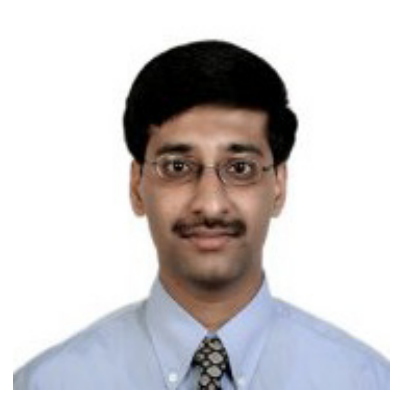

Shreyas Suresh Rao is pursuing Ph.D. in the department of Computer Science and Engineering at Manipal Institute of Technology, Manipal, India. He obtained his M.S in Software Systems from BITS, Pilani in 2007. His previous experience includes seven years of working at SLK Software Services Pvt. Ltd., Bangalore where he played various roles such as Business Analyst, Team Leader, Analyst/Designer, and had been involved in the execution of several end-to-end enterprise projects in Banking, Manufacturing, and Automobile domains. His technical expertise lies in ASP.NET technologies such as Web services, Web Form applications, Silverlight, and SharePoint. His research interests include knowledge engineering, enterprise architecture, crowdsourcing, and Web services. He can be contacted at shreyassureshrao@gmail.com.

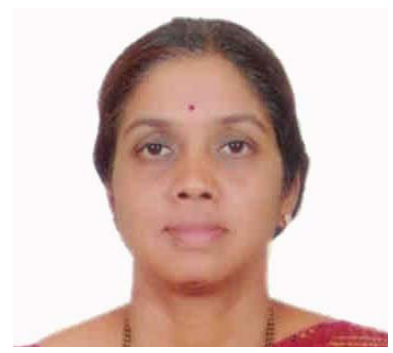

Ashalatha Nayak is a professor and currently heading the department of Computer Science and Engineering at Manipal Institute of Technology, Manipal, India. She obtained her Ph.D. from the School of Information Technology, IIT Kharagpur in the area of Model Based Testing. Her research interests include knowledge engineering, semantic Web, software testing, intelligent agents, and cloud security. She can be contacted at asha.navak@manipal.edu. 